Teaching and Learning, Vol 4, No. 3, 2008

\title{
Health Education Re-conceptualized and Its Implications for Ontario School Health Education Curriculum
}

\author{
Chunlei Lu: Brock University, Canada \\ "Prevention is more important than cure." ----Ancient Chinese saying
}

\begin{abstract}
The concepts of health and health education are culturally constructed. Thus it may be argued the operationalization of contemporary public health ideals as espoused in Canadian school systems is largely derived from a Western cultural perspective that privileges Euro-centric definitions of health and marginalizes others. There is a need to re-examine and re-conceptualize "health" and "health education" from a historical and global perspective in order to help in school health educators deepen and broaden public understanding of health and foster more representative and holistic approaches to the practice of health education. In ancient East (e.g., China, India), protecting and maintaining the integrity and balance or harmony of the human-nature unity was viewed as fundamental to maintaining and protecting health. This Eastern notion of health as a function of maintaining a balance in the forces that shape our lives is in fact a powerful theoretical foundation for legitimizing the establishment of health education programs in schools. Although the WHO definition of health has moved from the medical model to a much broader positive concept, it faces challenges for its Utopian ideology. The current Ontario health and physical education curriculum reasonably reflects the knowledge advanced in health education. Yet, there are still some crucial issues that need to be explored relating to health education, such as emphasis of health literacy, the role of mindfulness, spiritual health, and holistic health based on the new understanding of reconceptualized health and health education.
\end{abstract}

\section{Introduction}

A health crisis alarm is sounding across North America. As Rob Merrifield, the Chair of the Standing Committee on Health of the House of Commons of Canada declared, "For the first time in recorded history, our younger generation are expected to live shorter lives than their parents due to obesity. New and aggressive action is required to address this complex, and ultimately very costly, problem (House of Commons of Canada, 2007). Physically inactivity significantly worsens as children grow older, and Canada has received a failing D grade for the third straight year in 2007 (Active Healthy Kids Canada, 2007).

Obviously, the issue of public health has become a key focus of socio-economicpolitical discussion across North America. Health education is therefore regarded as a critical prevention and intervention vital to easing what is viewed as a growing crisis that needs to be urgently addressed (Grantham, 2007). However, while the concept of what it means to be human is delineated by an interplay of biological, psychological and sociological forces, the concepts of human health and health education are culturally constructed (Purnell \& Parlanka, 2003). Thus it may be argued the operationalization of contemporary public health ideals as espoused in Canadian school systems is largely derived from a Western cultural perspective that privileges Euro-centric definitions of health and marginalizes others. The implication therefore is that if the Canadian vision of 
a cultural mosaic is to accurately represent the peoples and cultures that comprise that mosaic, then there is a need to re-examine and re-conceptualize "health" and "health education" from a historical and global perspective in order to help in school health educators deepen and broaden public understanding of health and foster more representative and holistic approaches to the practice of health education.

\section{Western and Eastern Views of "health"}

The English word, "health", was derived from the old English word 'hoelth', which meant soundness of body, mind, or spirit (Hoad, 1996). "Hoelth" was traditionally considered a state of being free from illness or injury (Soanes \& Stevenson, 2003). Interestingly, the Germanic origin of the word health refers to a sense of wholeness, or a person's sense of being whole, sound or well (Harper, 2001) but that sense of wholeness seems somewhere along the line to have been lost in favour of a sense of being free from illness or disease.

Prior to Hippocrates (460-370 BCE), the "father of medicine" in the west, health was regarded as a gift of the gods and medicine was associated with theurgy or ritual practices aimed at invoking the blessing of the gods. Hippocrates developed modern western medicine by revolutionizing how health was conceived of in ancient Greece, moving the concept of health from the realm of ritual practice and philosophy towards a view that stressed observation and reason as a means of obtaining knowledge about how to achieve and maintain a healthy life. As a result the idea of health as a divine gift was replaced by the view that health resulted from balanced diets, personal hygiene, and environmental sanitation (Üstün \& Jakob, 2005).

At the same time that the European West was developing its ideas of health and medicine the people of the Oriental East were developing their own versions of what health and medicine should look like. In ancient China and India, human beings were thought of as elemental parts of an integrated whole that was both nature and the universe. Therefore, protecting and maintaining the integrity and balance or harmony of the human-nature relationship or unity was viewed as fundamental to maintaining and protecting health. In traditional Chinese medicine, for example the cause of poor health was often viewed as a weak, stagnant, and imbalanced "yin-yang qi" (defined loosely as the coherent essence of nature and mind that supports a harmonious universe). Therefore, prevention (i.e., maintaining or restoring strong balanced yin-yang qi) is viewed as more important than curing disease or illness. This Eastern notion of health as a function of maintaining a balance in the forces that shape our lives is in fact a powerful theoretical foundation for legitimizing the establishment of health education programs in schools.

However, these Eastern views conflict with a Western perspective dominated by Platonic and Cartesian philosophy that has until recently posited an unassailable dichotomy between human mind and body. One of the results of these differences in how health is viewed by West and East is that the primary explanatory model of illness in Western medicine focuses on abnormalities in the structure and function of bodily organs and systems whereas the approach taken by Eastern medicine focuses on maintaining holistic, balanced, and harmonious working relationships between and among the elements that support human health (Lu, Sylvestre, Melnychuk, \& Li, 2008). Just as in contemporary education theory which suggests that learning is more likely to take place in positive environments the Eastern view of health tends to rely more on positive views of health and health education than Western perspectives that focus on abnormality and disease. 
In North America, "health" has been defined according to World Health Organization (WHO) standards established in the late 1940s as a state of complete physical, mental, and social well-being, and not merely the absence of disease or infirmity. The WHO definition also represents health as a resource for everyday life, not the object of living, or in another sense as an active verb rather than a static noun (WHO, 1946). The WHO definition of health moves from the medical model to a much broader positive concept that emphasizes social and personal resources as well as physical capabilities. Specifically, this definition suggests that health is dynamic (shifting freely and frequently), subjective (reflecting widely different personal experiences), multidimensional (e.g., physical, mental, and social well-being), and multi-determined (a function of multiple factors including spiritual beliefs, social support, income, environment, politics, peace) (Public Health Agency of Canada, 2006a).

Since its origination formation in the mid 1940's the WHO definition of health has not changed in any essential way but it is now being challenged for its inclusion of the word "complete", which it is argued implies a utopian, inflexible, and unrealistic ideal that many people never achieve. Üstün \& Jakob (2005) propose as an alternative. Such a change would reflect a more Eastern perspective and approach to health and health education. Moreover, the ambiguity of boundaries (e.g., between mental and social wellbeing) inherent in the old WHO definition has also been critiqued because of a general vagueness that grants health promotion professionals unlimited options for the prevention and treatment of "poor health" (Public Health Agency of Canada, 2006a).

The concept or health or how it is defined also changes depending on its institutional application in a given society. For example in North American school health education textbooks, health is presented as the combination of physical, mental/emotional, and social well-being (Hilborn, Merki, Merki, Cleary, \& Middleton, 2004). "Being healthy" refers to striving to be the best a person can be at any given time (Hilborn, et al., 2004), while "well-being" is the ideal state of health would be one in which all of the various parts of the human organism function at an optimum level (Humphrey, 1998). The related term, "wellness", is defined as the quality of life that includes all aspects of health (Meeks, Heit, \& Page, 2007) or an overall state of well-being, or total health (Hilborn, et al. 2004).

The concept of "health" therefore can be said to be a sophisticated and complex cultural and individual construction because humans are biological, psychological, sociological, and cultural beings who are constantly adapting to their changing environments through social relationships and interactions with family, community, global society, cultural media and education systems in complex ways (Lu, Sylvestre, Melnychuk, \& Li, 2008; Purnell \& Parlanka, 2003). At every stage of life, health is determined by complex interactions between social and economic factors, the physical environment and individual behaviour. The factors that interact and intersect as "determinants of health" according to Health Canada's Population Health framework (Public Health Agency of Canada, 2006b), include 1) education, 2) culture, 3) biology and genetic endowment, 4) gender, 5) personal health practices, and coping Skills, 6) income and social status, 7) employment or working conditions, 8) social support networks, 9) social environments, 10) physical environments, 11) healthy child development, and 12) health services.

Considering the factors mentioned above and the other definitions health that have been presented, I would propose that health may best be defined as, a state of well-being 
influenced by physical, psychological, spiritual, social, cultural, and environmental aspects in a complex way.

\section{What is health education?}

Based on the definition of health proposed above, "health education" should be considered a complex process of helping individuals to develop necessary knowledge, skills, and attitudes in order to achieve and maintain good health. Human beings are not born inherently literate about health or healthy living. Thus, health literacy is an essential and integral part of general literacy that must be added to the lexicon of what constitutes a literate person in our society and implemented in schools, particularly in response to the rising health issues that are plaguing modern society. In Canada, health education is usually an independent school subject (except that health education is part of health and physical education curriculum in Ontario). Nevertheless, health education can also be implemented across the curriculum as well through other subjects such as, for example, science (e.g., biology), social studies, language arts, and math (Humphrey, 1998). In fact, the Ontario Ministry of Education has promoted some provocative integrated documents such as "Think literacy: Cross-curricular approaches (Grades 7-10). Subject-specific examples: Health and physical education" (Ontario Ministry of Education, 2004) and "Think literacy: Cross-curricular approaches (Grade 11-12). Subject-specific examples: Healthy active living" (Ontario Ministry of Education, 2005).

The central task in health education is to develop students' health literacy. Health literacy represents the cognitive and social skills that determine the motivation and ability of individuals to gain access to, understand, and use information in ways which promote and maintain good health (WHO, 1998). More recently, Anderson and Booth (2006) critically analyze the definitions of literacy and apply the key elements of literacy to health education. I suggest that "health literacy" refers to a person's ability to obtain and comprehend basic health information and services in order to promote his/her health and wellness. As indicated in Ontario health and physical education curriculum, students need to develop the "3 Cs", namely, comprehension (understanding), capacity (skills and knowledge), and commitment (action) of health literacy in health education in conjunction with physical education.

Aligning with the multiple dimensions of health proposed by scholars in the area of school health education, Telljohann, Symons, and Pateman (2006) adopt native Hawaiian framework of health to promote a model of balance, unity, and harmony in health Education. Similar to Eastern approaches, the native Hawaiians think about health through the "Lokahi Wheel" that consists of six interrelated aspects: physical (body), friends (family), thinking (mind), spiritual (soul), work (school), and feelings (emotion). The corresponding aspects of health education thus include 1) physical health (most conspicuous, prominent, important), 2) mental/intellectual health (e.g., interpret, analyze, act), 3) emotional health (e.g., feelings, expression), 4) social health (e.g., social environment), 5) spiritual health (e.g., meaning and purpose of life, value), and 6) vocational health (e.g., work). James Humphrey (1998) also discusses school health education in an integrated approach. He proposes three dimensions of health education 1) health knowledge (cognitive domain), 2) health attitudes (affective domain), and 3) health practices (action domain).

\section{Concluding remark}


In Canada, education is a provincial responsibility. The current Ontario health and physical education curriculum reasonably reflects the knowledge advanced in health education. For example, there three strands required in the elementary (Grade 1-9) health and physical curriculum, healthy living (e.g., healthy eating, growth and development, safety and injury prevention, and substance use and abuse, sexuality), active participation (e.g., physical activity, physical fitness, living skills), and fundamental movement skills (e.g., locomotion, manipulation, and stability). At the secondary school level, the strands are adjusted to similar but four sections, healthy living, active living, living skills, and physical activity. Also, mental health and social skills are introduced as early as Grade 4 (e.g., emotional changes), and the importance of these topics is increasingly emphasized as students' age. Moreover, societal and cultural factors that influence physical activity programs have been adequately articulated for the secondary school level in the current health and physical education curriculum. Yet, there are still some crucial issues that need to be explored and discussed relating to health and health education, such as emphasis of health literacy (see Anderson \& Booth 2006; WHO, 1998), the role of mindfulness (see Lu, 2007), spiritual health (see Anderson, 2007; Lodewyk, Lu, \& Kentel, 2007; Telljohann, Symons, \& Pateman, 2006), and holistic health (see Lu, 2006). Further research and discussion are needed if the dominant Canadian perspective on what health is and how it should be taught in our schools is to better reflect the beliefs of Canadians who share a global (e.g., East-West) perspective on health. 


\section{References}

Active Healthy Kids Canada (2007). The 2007 report card on physical activity for children and youth. Toronto: Active Healthy Kids Canada. Retrieved February 6, 2008 from

http://www.activehealthykids.ca/Ophea/ActiveHealthyKids_v2/programs_2007repo rtcard.cfm

Anderson, A. (2007). Spirituality as an integrated part of education for health. Physical and Health Education Journal, 73(1), 14-17.

Anderson, A., \& Booth, D. (2006). Health literacy. In E. Singleton \& A. Varpalotai (Eds.), Stones in the sneaker: Active theory for secondary school physical and health educators (pp.27-42). London, Ontario: The Althouse Press.

Grantham, A. (February 14, 2007). Childhood obesity. Speaking notes for Executive Director (Andrea Grantham) of Canadian Association for Health, Physical Education, Recreation, and Dance (CAHPERD). Ottawa: Standing Committee on Health of House of Commons of Canada

Hoad, T. F. (1996). The concise Oxford dictionary of English etymology. Oxford, NY: Oxford University Press.

Harper, D. (2001). Online etymology dictionary. http://www.etymonline.com/

Hilborn, M., Merki, M. B., Merki, D., Cleary, M. J., \& Middleton, K. (2004). Glencoe health ( $1^{\text {st }}$ Canadian ed.). Woodland Hills, CA: McGraw-Hill Ryerson.

House of Commons of Canada (March 27, 2007). Health committee targets childhood obesity. Ottawa: Canada House of Commons. Retrieved from February 6, 2008 from http://cmte.parl.gc.ca/cmte/CommitteePublication.aspx?SourceId=197932

Humphrey, J. (1998). Integration of health in the elementary school system. Commack, NY: Nova Science Publishers, Inc.

Lodewyk, K., Lu, C., Kentel, J. (2007). Reviving the spiritual dimension within a new health and physical education. Paper presented at the 2007 History and Future Direction of Research on Teaching and Teacher Education in Physical Education Conference. Pittsburgh, PA, October 11-14.

Lu, C. (2006). Eastern and Western approaches to physical and health education. In E. Singleton \& A. Varpalotai (Eds.), Stones in the sneaker: Active theory for secondary school physical and health educators (pp.71-85). London, Ontario: The Althouse Press.

Lu, C. (2007). Mindfulness: A new dimension in health and physical education. Paper presented at the CAHPERD conference. Moncton, NB.

Lu, C., Sylvestre, J., Melnychuk, N., \& Li, J. (2008). East meets West: ChineseCanadians' perspectives on health and fitness. Canadian Journal of Public Health, 99(1), 22-25.

Meeks, L., Heit, P., \& Page, R. (2007). Comprehensive school health education: Totally awesome strategies for teaching health ( $5^{\text {th }}$ ed.). New York, NY: McGraw-Hill. 
Ontario Ministry of Education (2004). Think literacy: Cross-curricular approaches (G7 10). Subject-specific examples: HPE. Retrieved March 12, 2008 from http:/www.edu.gov.on.ca/eng/studentsuccess/thinkliteracy/library.html

Ontario Ministry of Education (2005). Think literacy: Cross-curricular approaches ( $G$ 11-12). Subject-specific examples: Healthy active living. Retrieved March 12, 2008 from http://www.edu.gov.on.ca/eng/studentsuccess/thinkliteracy/library.html

Public Health Agency of Canada (2006a). What is health. Ottawa: Public Health Agency of Canada. Retrieved February 8, 2008 from http://www.canadian-healthnetwork.ca/servlet/ContentServer?pagename $=\mathrm{CHN}$ RCS/CHNResource/FAQCHNResourceTemplate\&cid=1001835

Public Health Agency of Canada (2006b). Determinants of health. Ottawa: Public Health Agency of Canada. Retrieved February 8, 2008 from http://www.phacaspc.gc.ca/media/nr-rp/2006/2006_06bk2-eng.php

Purnell, L. D., \& Parlanka, B. J. (Eds.) (2003). Transcultural health care: A culturally competent approach ( $2^{\text {nd }}$ ed.). Philadelphia, PA: F. A. Davis.

Soanes, C., \& Stevenson, A. (2003) (Eds.). Oxford Dictionary of English. New York, NY: Oxford University Press

Telljohann, S. K., Symons, C. W., \& Pateman B. (2006). Health Education: Elementary and middle school applications $\left(5^{\text {th }}\right.$ ed.). New York, NY: McGraw-Hill.

Üstün B., \& Jakob R. (2005). Re-defining “health”. Retrieved October 5, 2007 from http://www.who.int/bulletin/bulletin_board/83/ustun11051/en/print.html

WHO (1946). Preamble to the Constitution of the World Health Organization as adopted by the International Health Conference, New York, June 19-22, 1946; signed on July 22, 1946 by the representatives of 61 States (Official Records of the World Health Organization, no. 2, p. 100) and entered into force on April 7, 1948.

WHO (1998). Health promotion glossary. Geneva: The author. Retrieved February 8, 2008 from http://www.who.int/healthpromotion/about/HPR\%20Glossary\%201998.pdf 